\title{
Editorial: Re-thinking the future of semantic ambient media
}

\author{
Artur Lugmayr • Bjoern Stockleben • Thomas Risse • \\ Juha Kaario
}

Published online: 29 October 2011

(C) Springer Science+Business Media, LLC 2011

The term 'ambient media' is new in the field of media research in the context of smart and intelligent systems. As far the term was relating to advertising, but it's meaning goes far beyond. In ambient media, the natural environment is the media, and media objects are rendered throughout rather than on dedicated devices. Ambient media are 'intelligent' and react pro-actively to users - therefore we can refer to them as semantic ambient media. Ambient media underlie five basic principles: manifestation, morphing, intelligence, collaboration, and experience (see e.g. [1, 4, 5] or [3] for further reading). Within this special issue we focus on the investigation of ambient media and their characteristics in one article analyzing the other accepted five articles. Several articles adds either a human, technical, or philosophical viewpoint on ambient media.

The paper contributed by A. Scherp et al., entitled "A core ontology on events for representing occurrences in the real world" presents an ontology for the modeling of realworld events, and how they can be mapped to the digital overlay. B. Pogorelc et al. apply ambient media technology in a health care syste, recognizing health problems automatically. The ambient assisted living system shall prolong the autonomous living of the elderly. P. Codognet et al. approach ambient media from a audial viewpoint, and present a media installation, which generate sound spaces generated by self-organized agents. R.D. Vatavu et al. devote their research work to interactive surfaces and how emotional responses and

A. Lugmayr $(\bowtie)$

EMMi Lab, Tampere University of Technology (TUT), Tampere, Finland e-mail: artur.lugmayr@tut.fi

B. Stockleben

University of Applied Sciences Magdeburg, Magdeburg, Germany

e-mail: bjoern.stockleben@gmx.de

T. Risse

L3S Research Center, Hannover, Germany

e-mail: risse@13s.de

J. Kaario

Varaani Works Oy, Tampere, Finland

e-mail: Juha.kaario@varaani.com 
interactions allow new modalities for self-expression and emotional communication. A. Lugmayr has a more theoretical approach towards ambient media. He discusses the aspect of intelligence and wisdom in ambient media by applying Peirce's categories as framework.

A very specific feature of this special issue is a sixth article, which discusses and analyzes several articles that compile this special issue to provide a red-line through the discussed issues. Additional background literature, as e.g. [7] acted as input for this specific article.

For further reading or joining actively the activities for making ambient media reality, we would like to refer to activities as the Ambient Media Association (see http://www. ambientmediaassociation.org), the Semantic Ambient Media (SAME) workshop series (see e.g. [2] or [6]), or the Nokia Ubimedia MindTrek Award (see http://www.mindtrek.org/ ubimedia). We wish to give the reader new perspectives on this newly emerging field.

\section{References}

1. Lugmayr A (2007) Ambient media. Novatica 33(188):35-39

2. Lugmayr Artur, Stockleben Bjoern, Risse Thomas, Kaario Juha, and Laurila Kari, Acm multimedia 2008: 1 st workshop on semantic ambient media experiences (same2008) namu series. pages-, 2008.

3. Lugmayr A, Risse T, Stockleben B, Kaario J, Laurila K (2009) Re-Discussion of the Notion of Semantic Ambient Media-Reviewing Submissions to the 2nd SAME 2009 Workshop. In: Proceeding of the 2nd Workshop on Semantic Ambient Media Experiences (SAME 2009). AmI 2009, Salzburg, Austria

4. Lugmayr A, Risse T, Stockleben B, Kaario J, Laurila K (2009) Special issue on semantic ambient media experiences. Multimedia Tools and Applications 44(3):331-335

5. Lugmayr A, Risse T, Stockleben B, Laurila K, Kaario J (2009) Semantic ambient media — an introduction. Multimedia Tools and Applications 44:337-359. doi:10.1007/s11042-009-0282-Z

6. Lugmayr Artur, Risse Thomas, Stockleben Bjoern, Kaario Juha, and Pogorelc Bogdan, editors. Proceedings of the 3rd Semantic Ambient Media Experience (SAME) Workshop in Conjunction with AmI-10, number ISBN 978-952-15-2474-5. http://webhotel2.tut.fi.emmi.forum/files/library/ 201011_SAME_Proceedings_Small.pdf, Tampere Univ. of Technology (TUT), Tampere, Finland, 2010.

7. Tscheligi M, Obrist M, Lugmayr A (2008) 6th European Conference, EuroITV 2008-Changing Television Environments. Springer, Salzburg, Austria

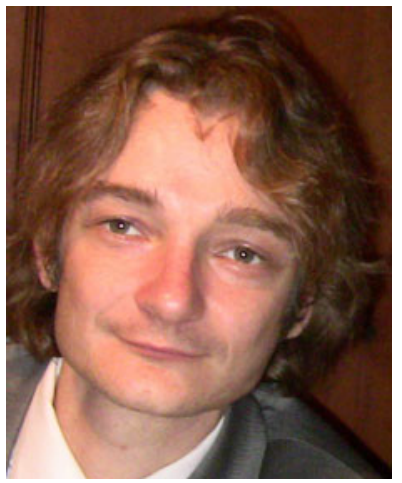

Artur Lugmayr Prof. Dr. Artur Lugmayr describes himself as a creative thinker and his scientific work is situated between art and science. Starting from July 2009 he is full-professor for entertainment and media production management at the Department of Business Information Management and Logistics at the Tampere University of Technology (TUT): EMMi - Entertainment and Media Production Management (http://webhotel2.tut.fi/emmi/ $\mathrm{web} /$ ). His vision can be expressed as to create media experiences on future emerging media technology platforms. He is the head and founder of the New AMbient MUltimedia (NAMU) research group at the Tampere University of Technology (Finland) which is part of the Finnish Academy Centre of Excellence of Signal 
Processing from 2006 to 2011 (http://namu.cs.tut.fi). He is holding a Dr.-Techn. degree from the Tampere University of Technology (TUT, Finland), and is currently engaged in Dr.-Arts studies at the School of Motion Pictures, TV and Production Design (UIAH, Helsinki). He chaired the ISO/IEC ad-hoc group "MPEG-21 in broadcasting"; won the NOKIA Award of 2003 with the text book "Digital interactive TV and Metadata" published by Springer-Verlag in 2004; representative of the Swan Lake Moving Image \& Music Award (http:// www.swan-lake-award.org); board member of MindTrek (http://www.mindtrek.org), EU project proposal reviewer; invited key-note speaker for conferences; organizer and reviewer of several conferences; and has contributed one book chapter and written over 25 scientific publications. His passion in private life is to be a notorious digital film-maker. He is founder of the production company LugYmedia Inc. (http://www.lugy-media. tv). More about him on http://www.tut.fi/emmi

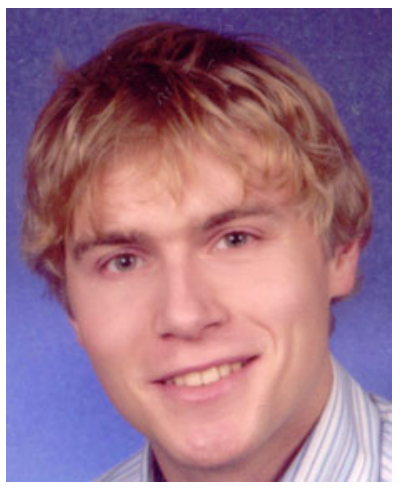

Bjoern Stockleben Björn Stockleben was awarded his master's degree in Media Sciences, Media Technology and Computer Sciences from Technical University of Brunswick and Brunswick School of Arts in 2003. For Rundfunk-Berlin Brandenburg he has been acting as technical manager in EC- and ESA-funded research projects such as IST-INSTINCT, IST-ENTHRONE and ARTES-COTV. He is an expert in participative media, interactive service authoring and non-linear AV media. Currently he works as scientific coordinator for the new master program "Cross Media", which combines management, journalism and interaction design at University of Applied Sciences Magdeburg-Stendal. He lectures in media theory at University of Applied Sciences Bremen and human-machine interaction at Technical University Brunswick.

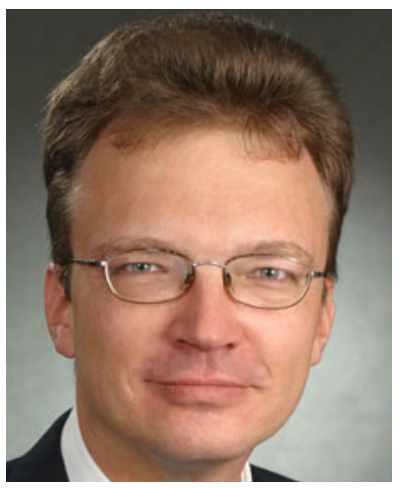

Thomas Risse Thomas Risse is the deputy managing director of the L3S Research Center in Hanover. He received a $\mathrm{PhD}$ in Computer Science from the Darmstadt University of Technology, Germany in 2006. Before he joined the L3S Research Center in 2007 he lead a research group about intelligent information environments at Fraunhofer IPSI, Darmstadt. Currently he is the scientific and technical director of the FP7 ARCOMEM project on Web archiving using social media information. Thomas Risse's research interests are 
semantic evolution, data management in distributed systems, and self-organizing systems. He serves regularly as program committee member or project reviewer. He published several papers at the relevant international conferences.

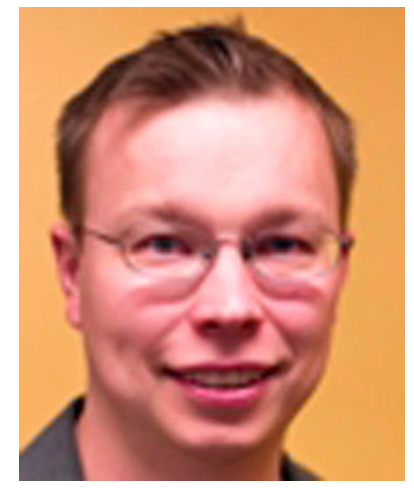

Juha Kaario Juha Kaario (MSc, MBA) is a Head of Business Development at Varaani Works Oy, a start-up founded in 2010. Previously he was a Senior Business Development Manager at the Nokia Research Center. He joined Nokia Mobile Phones marketing department in 1995 and moved to Nokia Research in 1997. In Nokia Research Center he has worked ten years as a research manager and senior research manager for several teams including Wearable Computing (1998-2002), Personal Content (2002-2003) and Mobile Games (2003-2007). Prior Nokia he has worked in the University of Tampere (1993-94), in the Technical Research Center of Finland (1992-93) and as a co-owner in a small enterprise (1993-1996). His interests are in cross discipline research for sustainable development, pervasive computing, social media and mobile services combined with business innovation. He is currently working in the Varaani Oy as a business developer and is the Chairman of the Board in another start-up, Newelo Oy. 